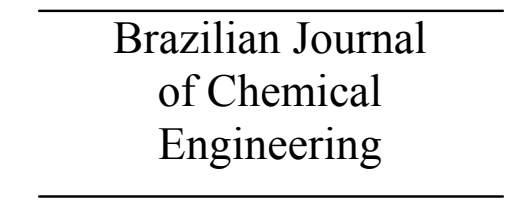

ISSN 0104-6632

Printed in Brazil

www.abeq.org.br/bjche

Vol. 28, No. 03, pp. 447 - 456, July - September, 2011

\title{
MASS TRANSFER PERFORMANCE IN PULSED DISC AND DOUGHNUT EXTRACTION COLUMNS
}

\author{
M. Torab-Mostaedi ${ }^{1 *}$, A. Ghaemi ${ }^{2}$, M. Asadollahzadeh ${ }^{1}$ and P. Pejmanzad ${ }^{1}$ \\ ${ }^{1}$ Nuclear Science and Technology Research Institute, Nuclear Fuel Cycle Research School, \\ Phone: (+9821) 88221128, Fax: (+9821) 88221116, End of North Karegar Av., \\ P.O. Box: 11365-8486, Tehran, Iran. \\ E-mail: mmostaedi@aeoi.org.ir \\ ${ }^{2}$ Department of Chemical Engineering, Iran University of Science and Technology, \\ P.O. Box: 16765-163, Tehran, Iran.
}

(Submitted: March 8, 2011 ; Revised: April 16, 2011 ; Accepted; April 19, 2011)

\begin{abstract}
Mass transfer performance is presented for a $76 \mathrm{~mm}$ diameter pulsed disc and doughnut extraction column for the toluene-acetone-water system. The experiments were carried out for both mass transfer directions. The mass transfer data are interpreted in terms of the axial diffusion model, thus accounting for continuous phase axial dispersion. The effect of operating parameters on the overall volumetric mass transfer coefficients has been investigated. The results show that the column performance increases with an increase in pulsation intensity. At high pulsation intensity, however, the overall volumetric mass transfer coefficient decreases due to the production of very fine dispersed droplets. It was also found that the column performance decreases with both an increase in dispersed phase velocity and a decrease in continuous phase velocity. An empirical correlation for prediction of the continuous phase overall mass transfer coefficient is derived in terms of the overall Sherwood number, Reynolds number and dispersed phase holdup for each mass transfer direction. The prediction of continuous phase overall mass transfer coefficients from the presented correlations is in good agreement with experimental data. Keywords: Mass transfer coefficient; Pulsed disc and doughnut column; Axial diffusion model; Holdup.
\end{abstract}

\section{INTRODUCTION}

Liquid-liquid extraction has long been a key operation in many separation processes found in the chemical, pharmaceutical, environmental, oil, food, nuclear, and hydrometallurgical industries for product purification and/or raw material recovery. Industrially, more than 25 kinds of liquid-liquid contactors have already been identified (Blass et al., 1986). Insofar as liquors from hydrometallurgical industries are concerned, on account of the slow extraction rates exhibited by most metal systems of practical interest, mixer-settlers have been frequently adopted. However, in recent years, the development of new extractants with superior selectivity and efficiency characteristics has led to an increasing interest in the use of agitated columns for the treatment of hydrometallurgical liquors (Moreira $e t$ al., 2005).

Recently, the pulsed disc and doughnut column has been installed in a number of metallurgical applications around the world; for example, at the Western Mining Corporation Olympic Dam operation in South Australia, ten columns have been operating for the extraction of uranium. It has also been used in the nuclear industry and in the chemical industry. This column has also been extensively applied to reprocess spent nuclear fuel in France and Japan (Angelov and Journe, 1990; Angelov et al., 1998). In comparison to mixer-settlers, the column has been stated to have several advantages, viz., its lower cost, simplicity of design, less space consumption, and reduction of organic loss (Movsowitz et al., 1997; Jahya et al., 1999).

*To whom correspondence should be addressed 
Having determined the column diameter, the mass transfer performance should next be considered in calculation of the column height. In early design procedures, ideal plug-flow conditions were assumed in both phases for the estimation of the height required for the desired separation. It is well-known that axial dispersion in one or two phases leads to considerable deviations from ideal plug-flow, resulting in an increase in the height required to achieve the design specification. Two distinct types of models are in use, namely the diffusion model, which assumes turbulent axial diffusion of solute superimposed on plug flow of the phase under consideration, and the backflow model, which assumes well-mixed non-ideal stages between which backflow occurs. Two models represent idealized limiting cases, but in practice the diffusion model is approached by differential extractors and the backflow models are developed for step-wise contactors, although the results for these two models are almost identical when the stage number of the backflow model is large enough. On this basis, the state of the art for the design and analysis of an extraction column is to use the diffusion or backflow model, where one parameter accounts for all deviations from the ideal plug flow behavior (Bart et al., 2008).

Many investigations have concentrated on the development of numerical solutions to describe the operational characteristics of the column (Aoun Nabli et al., 1998; Aoun Nabli and Guiraud, 1997; Bardin-Monnier and Guiraud, 2003); however, no firm design and scale-up criteria have yet been proposed and few data are available on the mass transfer performance of this type of column. For the purpose of establishing a proper design procedure for pulsed disc and doughnut extraction columns, there is thus a need for reliable correlations for prediction of the overall mass transfer coefficients.

This paper presents a study of the mass transfer performance of a pulsed disc and doughnut column. The effects of pulsation intensity, continuous and dispersed phase velocities, and mass transfer direction on the overall volumetric mass transfer coefficients are investigated. An empirical correlation for prediction of the overall mass transfer coefficients is derived in terms of the overall Sherwood number, Reynolds number and dispersed phase holdup.

\section{EXPERIMENTAL}

Figure 1 shows the schematic arrangement of the experimental apparatus. The main column section consisted a $74 \mathrm{~cm}$ long glass tube of $76 \mathrm{~mm}$ internal diameter, enclosing a stack of 30 pairs of discs and doughnuts, made of $2 \mathrm{~mm}$ stainless steel sheet. The discs and doughnuts were arranged alternately and spaced $10 \mathrm{~mm}$ apart, resulting in a $20 \mathrm{~mm}$ compartment height; they were held in place by means of three $3.2 \mathrm{~mm}$ o.d. SS tie rods with SS spacer sleeves. The discs were $67 \mathrm{~mm}$ in diameter and the doughnut apertures were $36 \mathrm{~mm}$, giving an open free area of $23.5 \%$. A settler $112 \mathrm{~mm}$ in diameter at each end of the column permitted the liquids to coalesce and decant separately. The column was pulsed by blowing air at the required amplitude and frequency into the pulse leg. The air pressure was controlled by a regulator to provide pulses of the required amplitude in the column while the frequency of the pulses was controlled by using two solenoid valves. The inlet and outlet of the column were connected to four tanks, each of 801 capacity. The flow rates of both phases were controlled via rotameters. The liquid-liquid interface was maintained approximately $250 \mathrm{~mm}$ above the top compartment. This was achieved by using an optical sensor. A solenoid valve (a normally closed type) was provided at the outlet stream of heavy phase. This valve received electronic signals from the sensor. When the interface location was going to change, the optical sensor sent a signal to the solenoid valve and the aqueous phase was allowed to leave the column by opening the diaphragm of the solenoid valve. The organic phase was allowed to leave the column via overflow.

A toluene-acetone-water system was used in this study. This system is recommended as a standard test system by the European Federation of Chemical Engineering (E.F.C.E.). Distilled water was used as the continuous phase and technical grade solvents of at least $99.9 \mathrm{wt} \%$ purity were used as the dispersed phase. The physical properties of the liquid-liquid systems used in the experiments are given in Table 1. It should be noted that, under mass transfer conditions, a degree of uncertainty surrounds the estimation of physical properties (particularly interfacial tension), since these vary not only with the solute concentrations, but also along the column. In this study, the values of physical properties have been assumed to correspond to the mean of acetone concentration in the continuous and dispersed phases. The mean value of the acetone concentration was obtained at the inlet and outlet of the column. Liquid-liquid equilibrium data of the liquid system were taken from Míšek et al. (1985).

When starting a run, the solvent and water phases were first mutually saturated, after which acetone was added to the dispersed or continuous phase to give a concentration of about $3.5 \mathrm{wt} \%$ acetone. Samples of each phase were taken at their inlets to the column and used for determination of the initial solute concentration. 


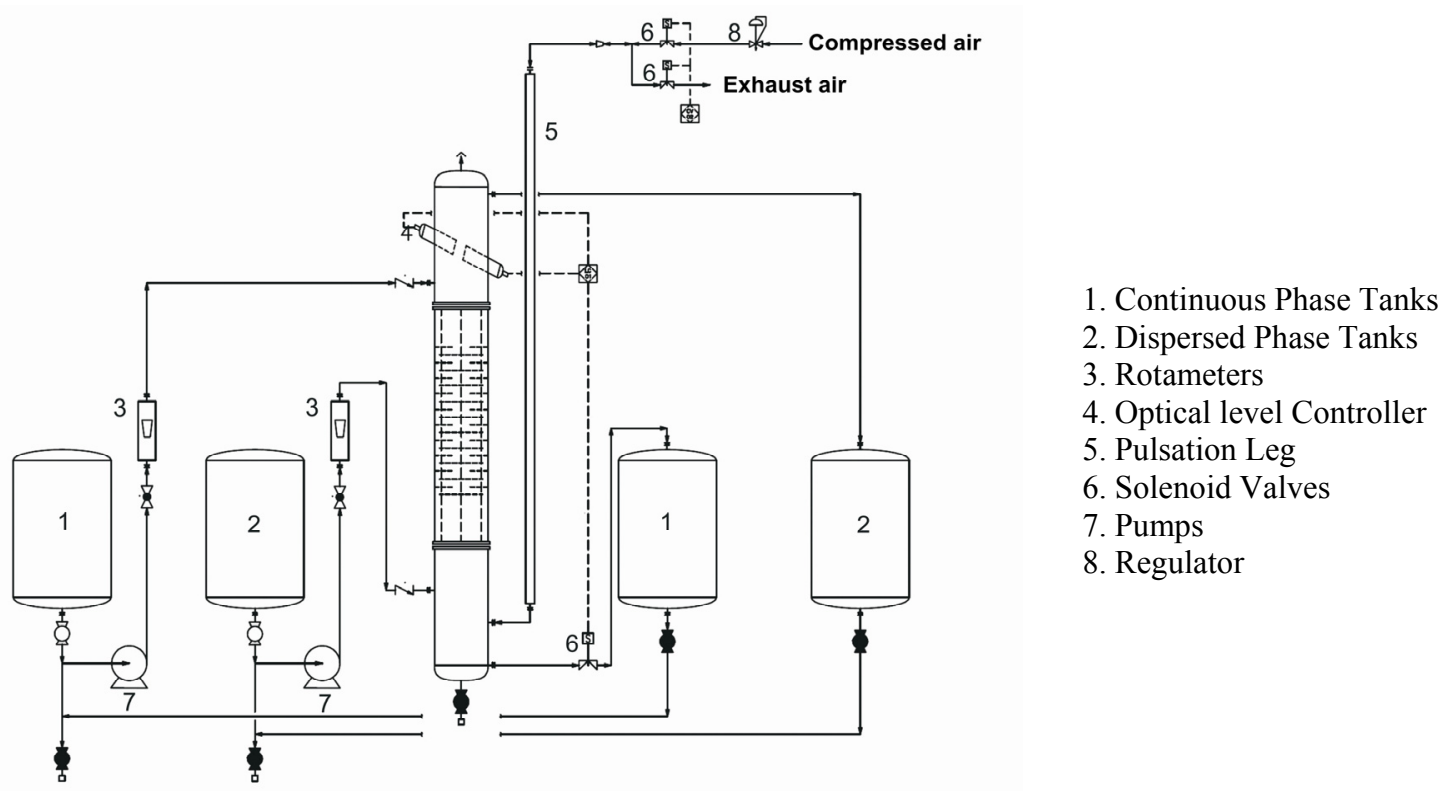

Figure 1: Schematic diagram of the pulsed disc and doughnut column

Table 1: Physical properties of the chemicals used at $20^{\circ} \mathrm{C}$ (Míšek et al., 1985).

\begin{tabular}{|c|c|}
\hline Physical property & Toluene-acetone-water \\
\hline$\rho_{\mathrm{c}}\left(\mathrm{kg} / \mathrm{m}^{3}\right)$ & $994.4-995.7$ \\
$\rho_{\mathrm{d}}\left(\mathrm{kg} / \mathrm{m}^{3}\right)$ & $864.4-865.2$ \\
$\mu_{\mathrm{c}}(\mathrm{mPa} . \mathrm{s})$ & $1.059-1.075$ \\
$\mu_{\mathrm{d}}(\mathrm{mPa} . \mathrm{s})$ & $0.574-0.584$ \\
$\sigma(\mathrm{mN} / \mathrm{m})$ & $27.7-30.0$ \\
$\mathrm{D}_{\mathrm{c}} \times 10^{9}\left(\mathrm{~m}^{2} / \mathrm{s}\right)$ & $1.09-1.14$ \\
$\mathrm{D}_{\mathrm{d}} \times 10^{9}\left(\mathrm{~m}^{2} / \mathrm{s}\right)$ & $2.7-2.8$ \\
\hline
\end{tabular}

The amplitude and frequency of pulsation were next adjusted to the desired values and, after filling the column with the continuous phase, the dispersed phase was introduced. The interface position was then maintained at the desired height, and the system was allowed to reach the steady state, which usually necessitated 4-5 changes of the column volume. At the end of each experiment, samples of the organic and aqueous phases were taken at their respective outlets. The solute concentrations were then determined by gas chromatography.

After reaching the steady state at the desired flow rate, the drops were photographed using a Nikon D5000 digital camera. Drop dimensions were then determined using AutoCAD software. For elliptical drops, both the vertical and horizontal axes were measured. Drop sizes were converted to absolute dimensions by comparing the measured values with the disc or doughnut thickness. Approximately 150 drops per photo were analyzed. Finally, the drops were classified into $0.1 \mathrm{~mm}$ size intervals, which were used to calculate the Sauter mean drop diameter, $\mathrm{d}_{32}$, as follows:

$\mathrm{d}_{32}=\frac{\sum_{\mathrm{i}=1}^{\mathrm{n}} \mathrm{n}_{\mathrm{i}} \mathrm{d}_{\mathrm{i}}^{3}}{\sum_{\mathrm{i}=1}^{\mathrm{n}} \mathrm{n}_{\mathrm{i}} \mathrm{d}_{\mathrm{i}}^{2}}$

Holdup measurements were obtained by using the shut down (displacement) method. In order to use this method, at the end of a run, the inlet and outlet valves were shut simultaneously and the dispersed phase was allowed to disengage to the interface at 
the top of the column. A period of 10-15 min was allowed for the dispersed phase to settle. The change in interface height between operation and after settling was measured and then converted into the corresponding volume to determine holdup.

Visual observation showed that mixer-settler, transition, and emulsion regimes exist in the column depending upon the flow rates and the pulse characteristics. However, experiments at pulsation intensities below $2.4 \mathrm{~cm} / \mathrm{s}$ were not performed as the main concern of the work was to determine the column performance under industrial operating conditions.

\section{MODELING}

Based upon the axial diffusion model and mass balance in the column over the differential elements of the column with total effective height $\mathrm{H}$, the set of equations for the steady state process was established as follows, for constant superficial velocities $V_{x}$ and $\mathrm{Vy}$ at any given pulsation intensity:

$\frac{\partial}{\partial Z}\left(x-\frac{1}{P_{x}} \frac{\partial x}{\partial Z}\right)+N_{o x}\left(x-x^{*}\right)=0$

$\frac{\partial}{\partial Z}\left(y+\frac{1}{P_{y}} \frac{\partial y}{\partial Z}\right)-N_{o x} \frac{V_{x}}{V_{y}}\left(x-x^{*}\right)=0$

where

$$
\begin{aligned}
& \mathrm{P}_{\mathrm{x}}=\mathrm{HV}_{\mathrm{x}} / \mathrm{E}_{\mathrm{x}}, \quad \mathrm{P}_{\mathrm{y}}=\mathrm{HV}_{\mathrm{y}} / \mathrm{E}_{\mathrm{y}}, \quad \mathrm{Z}=\mathrm{h} / \mathrm{H}, \\
& \mathrm{N}_{\mathrm{ox}}=\frac{\mathrm{k}_{\mathrm{ox}} \mathrm{aH}}{\mathrm{V}_{\mathrm{x}}} .
\end{aligned}
$$

In the present study, the dispersed phase axial dispersion was assumed to be negligible, i.e., $1 / P_{d}=0$, with the continuous phase axial mixing coefficient estimated by the following correlation given by Jahya et al. (2009):

$$
\mathrm{E}_{\mathrm{c}}=\mathrm{k}\left(\frac{\mu_{\mathrm{c}}}{\Delta \rho}\right)\left(\frac{\mathrm{A}}{\mathrm{h}_{\mathrm{c}}}\right)^{\mathrm{k}_{1}}\left(\frac{\mathrm{V}_{\mathrm{c}}}{\mathrm{Af}}\right)^{\mathrm{k}_{2}}\left(\frac{\mathrm{V}_{\mathrm{d}}}{\mathrm{V}_{\mathrm{c}}}\right)^{\mathrm{k}_{3}}\left(\frac{\mathrm{V}_{\mathrm{d}} \mu_{\mathrm{c}}}{\sigma}\right)^{\mathrm{k}_{4}}
$$

with $\mathrm{k}=3.263 \times 10^{6}, \mathrm{k}_{1}=0.246, \mathrm{k}_{2}=-0.157, \mathrm{k}_{3}=-0.681$ and $\mathrm{k}_{4}=1.062$ for the toluene-acetone-water system.

The three boundary conditions are as follows:
At the top of the column $(\mathrm{Z}=0)$ :

$$
-\frac{d x}{d Z}=P e_{x}\left(x^{\circ}-x\right)
$$

At the bottom of the column $(\mathrm{Z}=1)$ :

$$
\begin{aligned}
& \frac{d x}{d Z}=0 \\
& y=y^{\circ}
\end{aligned}
$$

By using the continuous phase axial dispersion coefficient, the measured dispersed and continuous phase concentrations, together with the equilibrium data, and the boundary conditions, the experimental values of continuous phase overall volumetric mass transfer coefficients $\left(\mathrm{k}_{\mathrm{oc}} \mathrm{a}\right)$ are calculated from Equations (2) and (3).

\section{RESULTS AND DISCUSSION}

The overall performance of an extraction column can be expressed in terms of the overall mass transfer coefficient, $\mathrm{k}_{\mathrm{oc}}$, and the interfacial area, a. The effect of pulsation intensity on the overall volumetric mass transfer coefficient is shown in Figure 2. As expected, a higher pulsation intensity results in a lower value of the average drop diameter and a higher value of the dispersed phase holdup. The interfacial area increases with both effects. However, the reduction of drop size results in a reduction of internal circulation and turbulence in the drops and, consequently, the overall mass transfer coefficient decreases with an increase in pulsation intensity. At low and medium values of the pulsation intensity, the effect of the interfacial area is larger than that of the overall mass transfer coefficient and, consequently, the overall column performance increases with an increase in pulsation intensity. At high values of the pulsation intensity, however, the overall mass transfer starts to fall significantly with the formation of rigid droplets. The column performance is also largely affected by the axial mixing at high values of the pulsation intensity. For this range of operating conditions, the volumetric overall mass transfer coefficient decreases with an increase in agitation rate. This suggested that an optimum point exists where the performance of the column increases initially with pulsation intensity and thereafter decreases as the circulating droplets become smaller and more rigid. 
Figure 2 also shows that the column performance varies with the direction of mass transfer. When the mass transfer occurs from the continuous to the dispersed phase, the concentration of the solute in the draining film between two approaching drops will be lower than in the surrounding continuous liquid. For mass transfer in the opposite direction, the concentration will be correspondingly higher. The resulting gradients of interfacial tension will retard drainage and inhibit coalescence in the former case and accelerate drainage and coalescence in the latter case. Therefore, the $\mathrm{c} \rightarrow \mathrm{d}$ transfer tends to produce smaller drops than that in the opposite direction. Smaller drop size results in an increase in both the dispersed phase holdup and the interfacial area for mass transfer in the direction of the continuous to dispersed phase $(\mathrm{c} \rightarrow \mathrm{d})$. However, the mass transfer performance in the case of $d \rightarrow c$ is higher than in the opposite direction $\mathrm{c} \rightarrow \mathrm{d}$, in spite of a lower interfacial area (lower holdup, larger drop size). This higher performance is a result of increased mass transfer rates in the droplets of bigger sizes due to the presence of oscillations created between the droplets, which is enhanced by the Marangoni effects (Gourdon and Casamatta, 1991; Torab-Mostaedi and Safdari, 2009).

The effect of dispersed phase velocity on the overall volumetric mass transfer coefficient is shown in Figure 3. The experiments show that the dispersed phase holdup increases with an increase in dispersed phase velocity. It was also observed that increasing the flow rate of the dispersed phase tends to increase

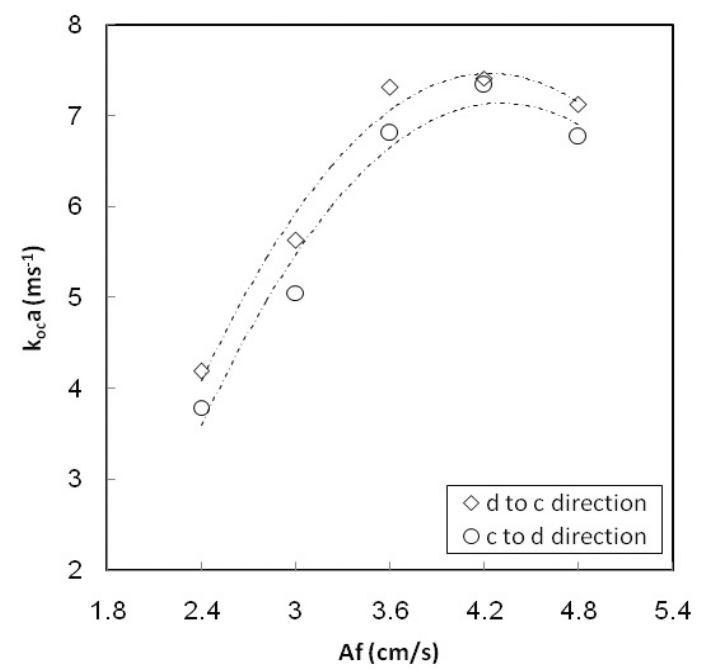

Figure 2: Variation in the mass transfer performance with pulsation intensity the average drop size, since a higher organic phase flow rate leads not only to a larger drop formation but also to higher coalescence frequencies. The interfacial area increases with an increase in holdup and decreases with mean drop diameter. In these experiments, it was observed that the effect of holdup on interfacial area is larger than that of drop size, i.e., interfacial area increases with an increase in dispersed phase velocity. However, the overall mass transfer coefficient decreases with an increase in dispersed phase velocity. In this case, it was found that the overall mass transfer coefficient is the dominant factor in determining the mass transfer performance and, consequently, the column performance decreases with increasing dispersed phase velocity.

The effect of continuous phase velocity on $\mathrm{k}_{\mathrm{oc}} \mathrm{a}$ is illustrated in Figure 4. The dispersed phase holdup increases with an increase in continuous phase velocity due to the increment of the drag force between dispersed drops and the continuous phase. The Sauter-mean drop diameter did not change significantly with progressive increases in the continuous phase flow rate. So, the interfacial area increases with an increase in holdup when the drop size is approximately constant. It was also observed that the overall mass transfer coefficient increases with an increase in continuous phase velocity. The mass transfer performance increases with an increase in both the overall mass transfer coefficient and the interfacial area. The operating variables and experimental results are listed in the Appendix.

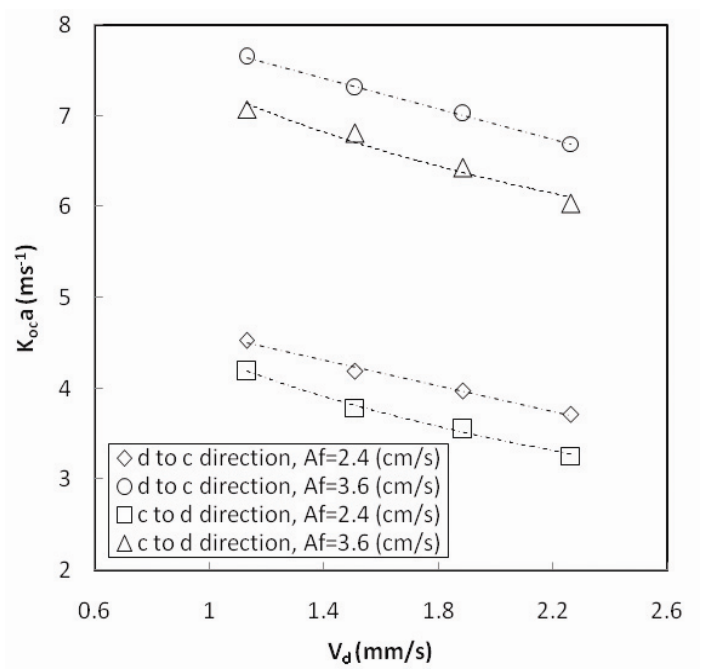

Figure 3: Variation in the mass transfer performance with dispersed phase velocity 


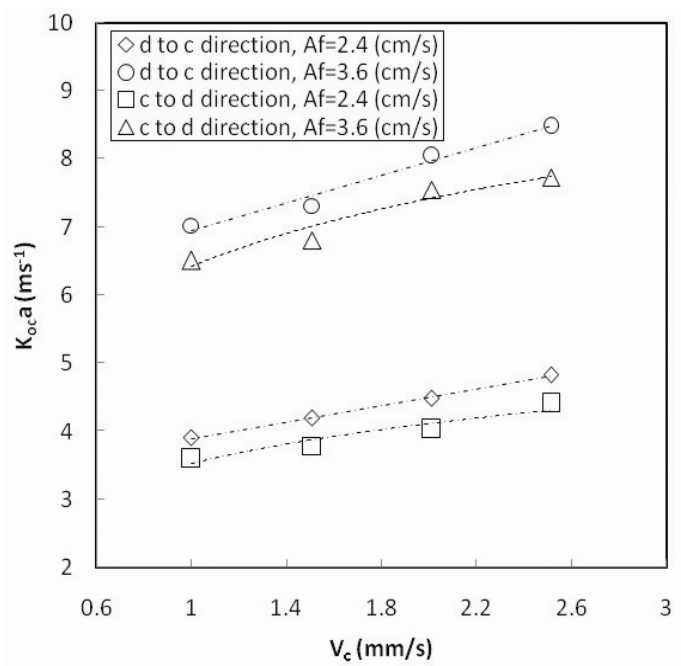

Figure 4: Variation in the mass transfer performance with continuous phase velocity

\section{Prediction of the Continuous Phase Overall Mass Transfer Coefficient}

One of the main objectives of this study is to propose an equation for prediction of the overall mass transfer coefficients in pulsed disc and doughnut columns. The continuous phase overall mass transfer coefficient $\left(\mathrm{k}_{\mathrm{oc}}\right)$ can be obtained by dividing the volumetric coefficient by the interfacial area $\left(a=6 x_{d} / d_{32}\right)$. For the description of mass transfer coefficients, Kumar and Hartland (1999) developed semi-empirical predictive correlations for the mass transfer coefficients of the continuous and dispersed phase in pulsed, Karr, Kühni and rotating disc columns, as represented by:

$$
\begin{aligned}
& \frac{\mathrm{Sh}_{\mathrm{c}} /\left(1-\mathrm{x}_{\mathrm{d}}\right)-\mathrm{Sh}_{\mathrm{c}, \mathrm{rigid}}}{\mathrm{Sh}_{\mathrm{c}, \infty}-\mathrm{Sh}_{\mathrm{c}} /\left(1-\mathrm{x}_{\mathrm{d}}\right)}= \\
& 5.26 \times 10^{-2} \mathrm{Re}^{1 / 3+6.59 \times 10^{-2} \operatorname{Re}^{0.25} \times} \\
& \mathrm{Sc}_{\mathrm{c}}^{1 / 3}\left(\frac{\mathrm{V}_{\mathrm{s}} \mu_{\mathrm{c}}}{\sigma}\right)^{1 / 3} \frac{1}{1+\kappa^{1.1}} \times\left[1+\mathrm{C}_{1}\left\{\frac{\psi}{\mathrm{g}}\left(\frac{\rho_{\mathrm{c}}}{\mathrm{g} \sigma}\right)^{0.25}\right\}^{1 / 3}\right] \\
& \mathrm{Sh}_{\mathrm{d}}=17.7+\frac{3.19 \times 10^{-3}\left(\operatorname{ReSc}_{\mathrm{d}}^{1 / 3}\right)^{1.7}}{1+1.43 \times 10^{-2}\left(\operatorname{ReSc}_{\mathrm{d}}^{1 / 3}\right)^{0.7}}\left(\frac{\rho_{\mathrm{d}}}{\rho_{\mathrm{c}}}\right)^{2 / 3} \times \\
& \frac{1}{1+\kappa^{2 / 3}} \times\left[1+\mathrm{C}_{2}\left\{\frac{\psi}{\mathrm{g}}\left(\frac{\rho_{\mathrm{c}}}{\mathrm{g} \sigma}\right)^{0.25}\right\}^{1 / 3}\right]
\end{aligned}
$$

where:

$$
\begin{aligned}
& \mathrm{Sh}_{\mathrm{c}, \text { rigid }}=2.43+0.775 \operatorname{Re}^{1 / 2} \mathrm{Sc}_{\mathrm{c}}^{1 / 3}+0.0103 \operatorname{ReSc}_{\mathrm{c}}^{1 / 3} \\
& \mathrm{Sh}_{\mathrm{c}, \infty}=50+\frac{2}{\sqrt{\pi}}\left(\mathrm{Pe}_{\mathrm{c}}\right)^{1 / 2} \\
& \psi=\frac{\pi^{2}\left(1-\varepsilon^{2}\right)}{2 \varepsilon^{2} \mathrm{C}_{\mathrm{o}}^{2} \mathrm{~h}_{\mathrm{c}}}(\mathrm{Af})^{3}
\end{aligned}
$$

where $\mathrm{C}_{1}=\mathrm{C}_{2}=4.33$ for pulsed columns. The overall mass transfer coefficient can be obtained via the twofilm model as follows:

$$
\frac{1}{\mathrm{k}_{\mathrm{oc}}}=\frac{1}{\mathrm{k}_{\mathrm{c}}}+\frac{\mathrm{m}}{\mathrm{k}_{\mathrm{d}}}
$$

Since no published correlations are available for prediction of mass transfer coefficient in pulsed disc and doughnut columns, the Kumar and Hartland correlations are commonly used for description of the mass transfer performance in pulsed disc and doughnut columns (Van Delden et al., 2006; Grinbaum, 2006). In the present work, the possibility of using these correlations for prediction of the overall mass transfer coefficient is examined. The comparison of experimental results with those calculated by the Kumar and Hartland correlations is shown in Figure 5. Van Delden et al. (2006) also used these correlations for description of mass transfer performance of extraction of caprolactam with toluene in a pulsed disc and doughnut column. 
They observed that these correlations satisfactorily described the separation performance of the process in a pulsed disc and doughnut column. Contrary to their observation, Figure 5 shows that the Kumar and Hartland correlations do not have enough accuracy for prediction of the overall mass transfer coefficients in the column.

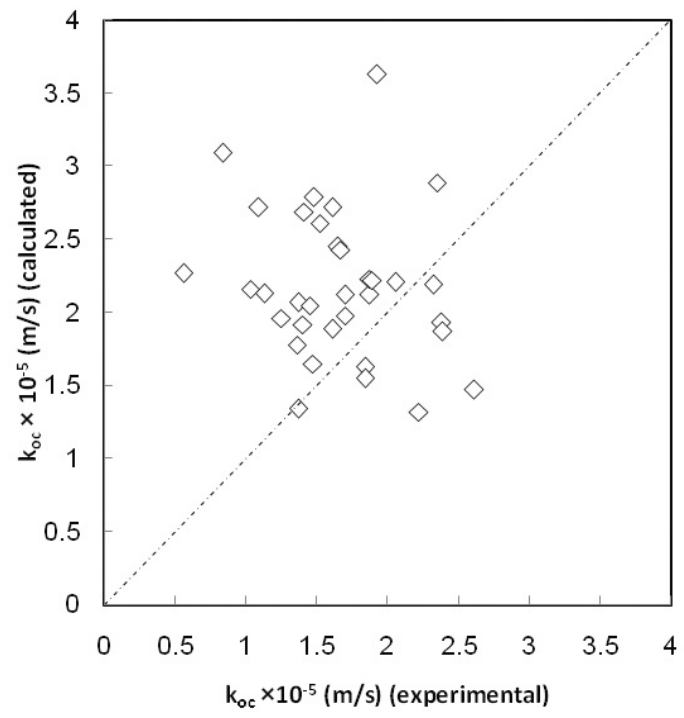

Figure 5: Comparison between experimental data and the predictions of the Kumar and Hartland correlations

For this reason, empirical correlations are derived for prediction of continuous phase overall mass transfer coefficients in terms of the overall Sherwood number, Reynolds number and dispersed phase holdup for different directions of mass transfer as follows:

$$
\begin{array}{r}
\operatorname{Sh}_{\mathrm{oc}}=-121.56+103.62 \operatorname{Re}^{0.16}\left(1-\mathrm{x}_{\mathrm{d}}\right) \\
(\mathrm{d} \rightarrow \mathrm{c}) \quad 11.73<\operatorname{Re}<69.43 \\
\mathrm{Sh}_{\mathrm{oc}}=-119.50+113.30 \operatorname{Re}^{0.12}\left(1-\mathrm{x}_{\mathrm{d}}\right) \\
(\mathrm{c} \rightarrow \mathrm{d}) \quad 9.45<\operatorname{Re}<57.08
\end{array}
$$

where

$$
\begin{aligned}
& \mathrm{Sh}_{\mathrm{oc}}=\frac{\mathrm{k}_{\mathrm{oc}} \mathrm{d}_{32}}{\mathrm{D}_{\mathrm{c}}} \\
& \operatorname{Re}=\frac{\mathrm{d}_{32} \mathrm{~V}_{\mathrm{s}} \rho_{\mathrm{c}}}{\mu_{\mathrm{c}}}
\end{aligned}
$$

in which $d_{32}$ is the Sauter-mean drop diameter and $V_{s}$ is the slip velocity between the two phases through the column. The correlation constants are calculated by using the least squares method with "Eviews software" version 3.1. Figure 6 shows the resulting comparison of experimental data with predicted results, using Equations (14) and (15). As can be seen in this figure, the suggested correlations estimate the experimental data with a relative deviation of $10.52 \%$.

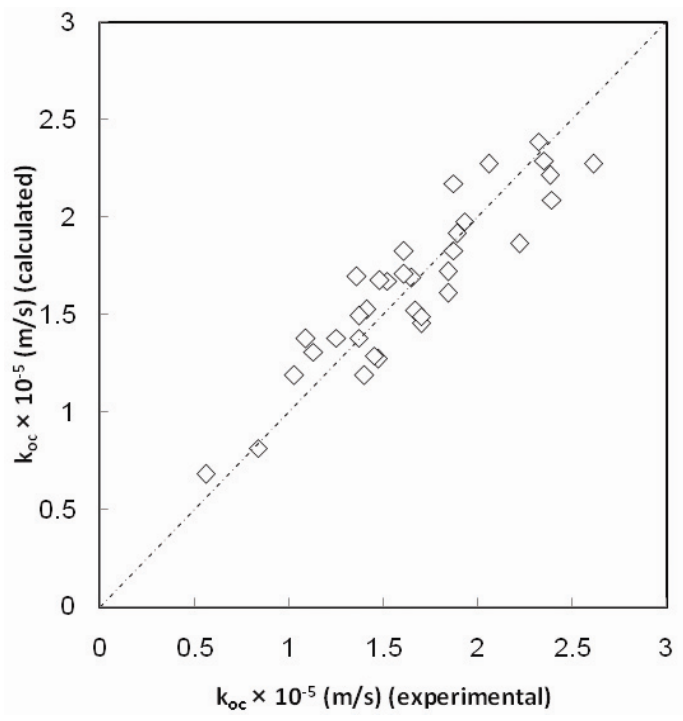

Figure 6: Comparison between experimental data and the predictions of Equations (14) and (15)

\section{CONCLUSIONS}

This study provides valuable information on the mass transfer performance of pulsed disc and doughnut columns, for which there are currently only limited results. The experiments show that the overall volumetric mass transfer coefficient increases with an increase in pulsation intensity. However, the mass transfer performance decreases at high values of the pulsation intensity due to increased entrainment and poor extraction efficiency, with the production of rigid dispersed droplets. The mass transfer performance is found to be higher for solute transfer in the direction of dispersed to continuous phase $(\mathrm{d} \rightarrow \mathrm{c})$ due to the induced effect of interfacial turbulence. The experimental findings indicate that the column mass transfer performance increases with an increase in continuous phase velocity and a decrease in dispersed phase velocity. An empirical correlation for prediction of the overall continuous phase Sherwood number is proposed based on the Reynolds number and dispersed phase holdup for each mass transfer direction. These correlations can be used for the design and scale-up of the column. 
NOMENCLATURE

\begin{tabular}{|c|c|}
\hline $\mathrm{a}$ & interfacial area \\
\hline A & amplitude of pulsation \\
\hline $\mathrm{C}$ 。 & orifice coefficient \\
\hline $\mathrm{C}_{1}, \mathrm{C}_{2}$ & $\begin{array}{l}\text { parameters of empirical } \\
\text { correlations }\end{array}$ \\
\hline $\mathrm{E}_{\mathrm{c}}$ & $\begin{array}{l}\text { continuous phase axial mixing } \\
\text { frequency }\end{array}$ \\
\hline $\mathrm{f}$ & frequency of pulsation \\
\hline g & acceleration due to gravity \\
\hline$h_{c}$ & compartment height \\
\hline $\mathrm{H}$ & effective height of the column \\
\hline $\begin{array}{l}\mathrm{k}, \mathrm{k}_{1}, \mathrm{k}_{2} \\
\mathrm{k}_{3}, \mathrm{k}_{4}\end{array}$ & constants, see Equation (4) \\
\hline $\mathrm{k}_{\mathrm{c}}$ & $\begin{array}{l}\text { continuous-phase mass } \\
\text { transfer coefficient }\end{array}$ \\
\hline $\mathrm{k}_{\mathrm{d}}$ & $\begin{array}{l}\text { dispersed-phase mass transfer } \\
\text { coefficient }\end{array}$ \\
\hline $\mathrm{k}_{\mathrm{oc}}$ & $\begin{array}{l}\text { overall continuous-phase mass } \\
\text { transfer coefficient }\end{array}$ \\
\hline $\mathrm{k}_{\mathrm{od}}$ & $\begin{array}{l}\text { overall dispersed-phase mass } \\
\text { transfer coefficient }\end{array}$ \\
\hline $\mathrm{N}_{\mathrm{ox}}$ & number of true transfer units \\
\hline $\mathrm{P}$ & Péclet number $=\mathrm{HV} / \mathrm{E}$ \\
\hline $\mathrm{Pe}_{\mathrm{c}}$ & $\begin{array}{l}\text { continuous-phase Péclet } \\
\text { number }=\mathrm{d}_{32} \mathrm{~V}_{\mathrm{s}} / \mathrm{D}_{\mathrm{c}}\end{array}$ \\
\hline $\operatorname{Re}$ & Reynolds number $=\mathrm{d}_{32} \mathrm{~V}_{\mathrm{s}} \rho_{\mathrm{c}} / \mu_{\mathrm{c}}$ \\
\hline $\mathrm{Sc}_{\mathrm{c}}$ & $\begin{array}{l}\text { continuous-phase Schmidt } \\
\text { number }=\mu_{\mathrm{c}} /\left(\rho_{\mathrm{c}} D_{\mathrm{c}}\right)\end{array}$ \\
\hline $\mathrm{Sc}_{\mathrm{d}}$ & $\begin{array}{l}\text { dispersed-phase Schmidt } \\
\text { number }=\mu_{d} /\left(\rho_{d} D_{d}\right)\end{array}$ \\
\hline $\mathrm{Sh}_{\mathrm{c}}$ & $\begin{array}{l}\text { continuous-phase Sherwood } \\
\text { number }=k_{c} d_{32} / D_{c}\end{array}$ \\
\hline $\mathrm{Sh}_{\mathrm{d}}$ & $\begin{array}{l}\text { dispersed-phase Sherwood } \\
\text { number }=k_{c} d_{32} / D_{c}\end{array}$ \\
\hline $\mathrm{Sh}_{\mathrm{oc}}$ & overall continuous-phase \\
\hline $\mathrm{V}$ & $\begin{array}{l}\text { Snerwood number }=\mathrm{K}_{\mathrm{oc}} \mathrm{C}_{32} / \mathrm{D}_{\mathrm{c}} \\
\text { superficial velocity }\end{array}$ \\
\hline $\mathrm{V}_{\mathrm{s}}$ & slip velocity \\
\hline$x_{d}$ & dispersed phase holdup \\
\hline $\mathrm{x}$ & $\begin{array}{l}\text { mass fraction of acetone in the } \\
\text { continuous phase }\end{array}$ \\
\hline$x^{*}$ & $\begin{array}{l}\text { equilibrium mass fraction of } \\
\text { acetone in the continuous } \\
\text { phase corresponding to the } \\
\text { dispersed phase }\end{array}$ \\
\hline $\mathrm{y}$ & $\begin{array}{l}\text { mass fraction of acetone in the } \\
\text { dispersed phase }\end{array}$ \\
\hline
\end{tabular}

\section{Greek Symbols}

$\begin{array}{ll}\sigma & \text { interfacial tension } \\ \Delta \rho & \text { density difference between }\end{array}$ phases

viscosity

density

viscosity ratio

Pa.s

$\mathrm{kg} \mathrm{m}^{-3}$

$(-)$

fractional free area

power dissipated per unit $\quad \mathrm{m}^{2} \mathrm{~s}^{-3}$

mass

$\mathrm{m}^{2} \mathrm{~s}^{-1}$

$\mathrm{m} \mathrm{s}^{-1}$

Subscripts

c continuous phase

d dispersed phase

$\mathrm{m} \quad \mathrm{x} \quad \mathrm{x}$-phase (continuous phase

$(-) \quad$ in the present case)

$\mathrm{m} \mathrm{s}^{-1} \quad \mathrm{y} \quad \mathrm{y}$-phase (dispersed phase

in the present case)

\section{$\mathrm{m} \mathrm{s}^{-1} \quad$ Superscripts}

$\mathrm{s}^{-1} \quad * \quad$ equilibrium value

- inlet to column

\section{REFERENCES}

Angelov, G. and Journe, E., Simulation of the flow patterns in a disc and doughnut column. Chem. Eng. J., 45, 87-97 (1990).

Angelov, G., Gourdon, C. and Line, A., Simulation of flow hydrodynamics in a pulsed solvent extraction column under turbulent regimes. Chem. Eng. J., 71, 1-9 (1998).

Aoun Nabli, M. S., Guiraud, P. and Gourdon, C., CFD contribution to a design procedure for disc and doughnut extraction columns. Chem. Eng. Res. Des., (Part A), 76, 951-960 (1998).

Aoun Nabli, M. S. and Guiraud, P., Numerical experimentation: a tool to calculate the axial dispersion coefficient in discs and doughnuts pulsed solvent extraction column. Chem. Eng. Sci., 52, 2353-2368 (1997).

Bardin-Monnier, N. and Guiraud, P., Lagrangian simulations contribution to the knowledge of discs and doughnuts pulsed solvent extraction columns hydrodynamics. Chem. Eng. Process, 42, 503-516 (2003).

Bart, H. -J., Drumm, C. and Attarahih, M. M., Process intensification with reactive extraction columns. Chem. Eng. Process, 47, 745-754 (2008).

Blass, E., Goldman, G., Hirschemann, K., Mihailowitsch, P., and Pietzsch, W., Progress in liquid-liquid extraction. Ger. Chem. Eng., 9, 222238 (1986). 
Gourdon, C. and Casamatta, G., Influence of mass transfer direction on the operation of a pulsed sieve-plate pilot column. Chem. Eng. Sci., 46, 2799-2808 (1991).

Grinbaum, B., Review Article: The existing models for simulation of pulsed and reciprocating columns-How well do they work in the real world? Solvent Extr. Ion Exc., 24, 795-82 (2006).

Jahya, A., Stevens, G. W. and Pratt, H. R. C., Flood point and dispersed phase holdup in a pulsed disc and doughnut liquid-liquid extraction column. In Proceedings Chemeca '99, Newcastle, Australia (1999).

Jahya, A., Stevens, G. W. and Pratt, H. R. C., Pulsed disc-and-doughnut column performance. Solvent Extr. Ion Exc., 27, 63-82 (2009).

Kumar, A. and Hartland, S., Correlations for prediction of mass transfer coefficients in single drop systems and liquid-liquid extraction columns. Chem. Eng. Res. Des. (Part A), 77, 372-384 (1999).
Míšek, T., R. Berger and J. Schröter, Standard test systems for liquid extraction studies. EFCE Publ. Ser., 46, 1 (1985).

Moreira, É, Pimenta, L. M., Carneiro, L. L., Faria, R. C. L. and Mansur, M. B., Ribeiro, C. P. Jr., Hydrodynamic behavior of a rotating disc contactor under low agitation conditions. Chem. Eng. Comm., 192, 1017-1035 (2005).

Movsowitz, R. L., Kleinberger, R. and Buchalter, E. M., Application of Bateman pulse columns for uranium solvent extraction. Bateman Projects Ltd., Israel (1997).

Torab-Mostaedi, M. and Safdari, J., Mass transfer coefficients in pulsed packed extraction column. Chem. Eng. Process, 48, 1321-1326 (2009).

Van Delden, M. L., Vos, G. S., Kuipers, N. J. M., and de Haan, A. B., Extraction of caprolactam with toluene in a pulsed disc and doughnut column, Part III: Mass transfer characteristics. Solvent Extr. Ion Exc., 24, 539-564 (2006).

\section{APPENDIX}

The experimental values obtained in the present work are listed in Tables A-1 and A-2.

Table A -1: Experimental data obtained in the experiments (mass transfer in the direction of dispersed to continuous phase)

\begin{tabular}{|c|c|c|c|c|c|c|c|}
\hline No. & $\mathbf{A}(\mathbf{c m})$ & $\mathbf{f}(\mathbf{1} / \mathbf{s})$ & $\mathbf{Q}_{\mathbf{c}}(\mathbf{I} / \mathbf{h})$ & $\left.\mathbf{Q}_{\mathbf{d}} \mathbf{(} / \mathbf{h}\right)$ & $\mathbf{x}_{\mathbf{d}}$ & $\mathbf{d}_{\mathbf{3 2}}(\mathbf{m m})$ & $\mathbf{k}_{\mathbf{o c}} \mathbf{( m / \mathbf { s } )}$ \\
\hline 1 & 1.2 & 2 & 24 & 24 & 0.0818 & 2.76 & $2.35 \times 10^{-5}$ \\
2 & 1.2 & 2.5 & 24 & 24 & 0.108 & 2.22 & $1.93 \times 10^{-5}$ \\
3 & 1.2 & 3 & 24 & 24 & 0.128 & 1.73 & $1.65 \times 10^{-5}$ \\
4 & 1.2 & 3.5 & 24 & 24 & 0.1388 & 1.22 & $1.09 \times 10^{-5}$ \\
5 & 1.2 & 4 & 24 & 24 & 0.1492 & 1.05 & $8.35 \times 10^{-6}$ \\
6 & 1.2 & 2 & 24 & 18 & 0.073 & 2.53 & $2.61 \times 10^{-5}$ \\
7 & 1.2 & 2 & 24 & 30 & 0.0923 & 2.87 & $2.05 \times 10^{-5}$ \\
8 & 1.2 & 2 & 24 & 36 & 0.1029 & 3.12 & $1.87 \times 10^{-5}$ \\
9 & 1.2 & 3 & 24 & 18 & 0.1214 & 1.62 & $1.70 \times 10^{-5}$ \\
10 & 1.2 & 3 & 24 & 30 & 0.1425 & 1.85 & $1.52 \times 10^{-5}$ \\
11 & 1.2 & 3 & 24 & 36 & 0.153 & 2.04 & $1.48 \times 10^{-5}$ \\
12 & 1.2 & 2 & 16 & 24 & 0.0765 & 2.73 & $2.32 \times 10^{-5}$ \\
13 & 1.2 & 2 & 32 & 24 & 0.087 & 2.78 & $2.38 \times 10^{-5}$ \\
14 & 1.2 & 2 & 40 & 24 & 0.095 & 2.81 & $2.39 \times 10^{-5}$ \\
15 & 1.2 & 3 & 16 & 24 & 0.124 & 1.72 & $1.61 \times 10^{-5}$ \\
16 & 1.2 & 3 & 32 & 24 & 0.1398 & 1.745 & $1.67 \times 10^{-5}$ \\
17 & 1.2 & 3 & 40 & 24 & 0.1451 & 1.75 & $1.70 \times 10^{-5}$ \\
\hline
\end{tabular}


Table A -2: Experimental data obtained in the experiments (mass transfer in the direction of continuous to dispersed phase)

\begin{tabular}{|c|c|c|c|c|c|c|c|}
\hline No. & $\mathbf{A}(\mathbf{c m})$ & $\mathbf{f}(\mathbf{1} / \mathbf{s})$ & $\mathbf{Q}_{\mathbf{c}}(\mathbf{I} / \mathbf{h})$ & $\left.\mathbf{Q}_{\mathbf{d}} \mathbf{(} / \mathbf{h}\right)$ & $\mathbf{x}_{\mathbf{d}}$ & $\left.\mathbf{d}_{\mathbf{3 2}} \mathbf{( m m}\right)$ & $\mathbf{k}_{\mathbf{o c}}(\mathbf{m} / \mathbf{s})$ \\
\hline 1 & 1.2 & 2 & 24 & 24 & 0.0886 & 2.63 & $1.87 \times 10^{-5}$ \\
2 & 1.2 & 2.5 & 24 & 24 & 0.122 & 2.04 & $1.41 \times 10^{-5}$ \\
3 & 1.2 & 3 & 24 & 24 & 0.137 & 1.65 & $1.37 \times 10^{-5}$ \\
4 & 1.2 & 3.5 & 24 & 24 & 0.141 & 1.19 & $1.03 \times 10^{-5}$ \\
5 & 1.2 & 4 & 24 & 24 & 0.162 & 0.92 & $5.60 \times 10^{-6}$ \\
6 & 1.2 & 2 & 24 & 18 & 0.0775 & 2.47 & $2.22 \times 10^{-5}$ \\
7 & 1.2 & 2 & 24 & 30 & 0.0985 & 2.68 & $1.61 \times 10^{-5}$ \\
8 & 1.2 & 2 & 24 & 36 & 0.113 & 2.84 & $1.36 \times 10^{-5}$ \\
9 & 1.2 & 3 & 24 & 18 & 0.1275 & 1.60 & $1.47 \times 10^{-5}$ \\
10 & 1.2 & 3 & 24 & 30 & 0.148 & 1.73 & $1.25 \times 10^{-5}$ \\
11 & 1.2 & 3 & 24 & 36 & 0.162 & 1.82 & $1.13 \times 10^{-5}$ \\
12 & 1.2 & 2 & 16 & 24 & 0.0826 & 2.60 & $1.89 \times 10^{-5}$ \\
13 & 1.2 & 2 & 32 & 24 & 0.0967 & 2.66 & $1.84 \times 10^{-5}$ \\
14 & 1.2 & 2 & 40 & 24 & 0.1065 & 2.67 & $1.84 \times 10^{-5}$ \\
15 & 1.2 & 3 & 16 & 24 & 0.128 & 1.62 & $1.37 \times 10^{-5}$ \\
16 & 1.2 & 3 & 32 & 24 & 0.145 & 1.67 & $1.45 \times 10^{-5}$ \\
17 & 1.2 & 3 & 40 & 24 & 0.1542 & 1.675 & $1.40 \times 10^{-5}$ \\
\hline
\end{tabular}

